\title{
Preparedness for eHealth: Health Sciences Students' Knowledge, Skills, and Confidence
}

\author{
Mary K. Lam, Monique Hines, Robyn Lowe, Srivalli Nagarajan, \\ Melanie Keep, Merrolee Penman, and Emma Power \\ Faculty of Health Sciences, The University of Sydney, \\ Sydney, Australia
}

\author{
mary.lam@sydney.edu.au monique.hines@sydney.edu.au \\ robyn.lowe@sydney.edu.au srivalli.nagarajan@sydney.edu.au \\ melanie.keep@sydney.edu.au merrolee.penman@sydney.edu.au \\ emma.power@sydney.edu.au
}

\begin{abstract}
There is increasing recognition of the role eHealth will play in the effective and efficient delivery of healthcare. This research challenges the assumption that students enter university as digital natives, able to confidently and competently adapt their use of information and communication technology (ICT) to new contexts. This study explored health sciences students' preparedness for working, and leading change, in eHealth-enabled environments. Using a cross-sectional study design, 420 undergraduate and postgraduate students participated in an online survey investigating their understanding of and attitude towards eHealth, frequency of online activities and software usage, confidence learning and using ICTs, and perceived learning needs. Although students reported that they regularly engaged with a wide range of online activities and software and were confident learning new ICT skills especially where they have sufficient time or support, their understanding of eHealth was uncertain or limited. Poor understanding of and difficulty translating skills learned in personal contexts to the professional context may impair graduates ability to confidently engage in the eHealth-enabled workplace. These results suggest educators need to scaffold the learning experience to ensure students build on their ICT knowledge to transfer this to their future workplaces.
\end{abstract}

Keywords: Allied health, eHealth, Technology, ICT, Health sciences, Higher education, Internet, Survey, Telehealth, Telemedicine

\section{Introduction}

Material published as part of this publication, either on-line or in print, is copyrighted by the Informing Science Institute. Permission to make digital or paper copy of part or all of these works for personal or classroom use is granted without fee provided that the copies are not made or distributed for profit or commercial advantage AND that copies 1) bear this notice in full and 2) give the full citation on the first page. It is permissible to abstract these works so long as credit is given. To copy in all other cases or to republish or to post on a server or to redistribute to lists requires specific permission and payment of a fee. Contact Publisher@InformingScience.org to request redistribution permission.
eHealth is a burgeoning area of practice spanning telehealth, internet-based and mobile disease/disability management programs, and the use of electronic health records (Eysenbach \& ConsorteHealth Group, 2011). Globally, there is increasing recognition of the central role eHealth will play in the current and future health workforce (World Health Organization [WHO] \& International 
Telecommunication Union [ITU], 2012). For example, Australia's National eHealth Strategy (Australian Government, Department of Health, 2012) and the European Commission's (2011) eHealth Action Plan have identified a need to equip future health professionals for practice in an increasingly eHealth-enabled healthcare environment. The key players of health workforce include medical doctors, nurses, and allied health practitioners (tertiary qualified health professionals whose skills and knowledge are used to maintain and restore health) (Lowe, Adams, \& O'Kanne, 2007).

In response to this identified need, Dattakumar, Gray, Henderson, Maeder, and Chenery (2012) reviewed health courses' accreditation requirements, health employer expectations, and higher education curricula to evaluate the eHealth competency of Australian health graduates. They found that, although accreditation requirements of health degrees (generally) did not explicitly state eHealth as a core competency, employers expect graduates to be able to engage with technology in healthcare. Further, there was mixed feedback about the degree of eHealth training provided to students at university. One potential explanation for not explicitly addressing eHealth competencies in university curricula is the assumption that students, having grown up with technology, are (a) confident and competent users of technology and (b) naturally able to apply their skills to the healthcare context. The term "digital natives" was coined to describe the generation of students who have not known a world without technology such as computers, mobile phones, digital music devices, and video games (Prensky, 2001). Prensky argued these students, with their sophisticated understanding of information and communication technology (ICT), think about, process, and approach learning differently from their predecessors. These students "are clamouring for these technologies to be used as part of their education, in part because they are things that the students have already mastered and use in their daily lives, and in part because they realise just how useful they can be" (Prensky, 2007, p. 41). The implication of Prensky's position is that digital natives may not require explicit, formal education in ICT, entering university with the knowledge and skills to successfully integrate ICT into the healthcare contexts.

Despite the academics' expectation that students come to university equipped with ICT skills, there is consistent evidence to challenge the assumptions made about digital natives. "Digital natives" are not a homogeneous group with the same levels of experience and expertise with using technology (Brown \& Czerniewicz, 2010). Kvavik (2005) found that preference for using ICT in learning was not predicted by students' level of technology use or their skill level. Moreover, students' competence using readily available technology for social purposes does not necessarily transfer to other technology or contexts (Katz, 2005; Kirkwood \& Price, 2005). In a recent study of 75,306 university students from a range of disciplines and degrees across 15 countries, Dahlstrom and Bischel (2014) found that only two thirds of students felt adequately prepared to meet the technological requirements of their university study. Earlier, Dahlstrom, Walker, and Dziuban (2013) reported that students, although confident in their use of ICT, expressed a need for further training to be work-ready. Together, these findings show that many students from the general student population are experienced ICT users, confident in their ability to use everyday technologies, but require support to understand how to use these skills outside social contexts.

Similarly, health professionals have also reported confidence in using technology while expressing concerns about how ICT can be used in their practice (Chedid, Dew, \& Veitch, 2013). Despite reporting that they are proficient and accepting of ICT more broadly, some occupational therapists are unsure that computer mediated healthcare will be as effective as face to face mode for delivering therapy and improving client outcomes (Chedid et al., 2013). Such findings suggest that further education and professional development of health professionals is required to facilitate the transfer of general ICT skills into the healthcare context and to achieve much wider acceptance/adoption of ICT within health workplaces. 
In addition to transferring ICT knowledge and skills into their academic learning, health sciences students face an additional challenge of translating this knowledge to new and unfamiliar healthcare contexts. If students are not adequately prepared at university to use ICTs in the health workplace, early career health professionals may rely on ad-hoc, unstructured learning about ICTs from colleagues whilst on-the-job (Gray \& Sim, 2011). Such approaches, whilst providing them with just enough knowledge of ICTs to function, are inefficient, patchy, and unlikely to position health professionals to become leaders in eHealth adoption and implementation (Gray \& Sim, 2011).

Within some healthcare settings eHealth uptake by allied health professions has been slow. Amongst clinicians, there are reservations concerning the robustness of health ICT systems (Department of Health and Ageing, 2011), the organizational and technical support available (Lluch, 2011), and the quality of care when services are provided remotely (Chedid et al., 2013). Therefore the opportunity for students to observe eHealth being used, in some cases, may be limited. As eHealth implementation in healthcare settings is only just emerging, students may be less likely to experience using technology for healthcare during work integrated learning placements. Given this potential lack of experience, students' understanding of what eHealth is and how it can be used for healthcare may also be limited.

There is very little research investigating students' understanding of eHealth. What exists comes mostly from the medical (Edirippulige et al., 2007; Hercigonja-Szekeres, Ilakovac, \& Šolić, 2012) and nursing literature (Clark, Baker, \& Baker, 2009; Edirippulige, Smith, Beattie, Davies, $\&$ Wootton, 2007-2008). Edirippulige et al. (2007-2008) found over 75\% of second year nursing students were not familiar with the terms "eHealth" and "online health" or its relevance to their future practice, rating their knowledge of eHealth technologies as minimal. Clark et al. (2009) extended on this research using a larger sample, finding nearly $40 \%$ of nursing students surveyed rated their understanding of eHealth as "poor" or "very poor" while three quarters of students reported "very good" or "good" basic computer skills. These studies, however, do not shed light on what students actually conceive as "eHealth". Students were asked to rate their familiarity with the term "online health" and their knowledge of eHealth but not asked to define eHealth, nor how its tools can be used.

Health professionals, themselves, have a limited understanding of eHealth. Eley, Fallon, Soar, Buikstra and Hegney (2009) surveyed Australian nurses on their perceived barriers to eHealth adoption. Participants' responses suggested that their interpretation of eHealth involved entering patient data into an electronic system. Although electronic health records are one component of eHealth, such responses suggest a limited understanding of the breadth of technology applications in health and healthcare. Health professionals' awareness of eHealth is important as they will shape students' knowledge of, and receptiveness to, the use of technology in healthcare.

For education to be relevant and promote lifelong learning it must recognize, value, and build upon students' prior knowledge (Knowles, 1990). Gaining insight into how allied health students currently conceive eHealth and the scope of their understanding of the term and associated tools and activities is important for curricula development. At present, there are gaps in our knowledge about students' understanding of eHealth, and it is also unclear how generalizable findings from the nursing discipline are to allied health students. Now, as many countries and organizations embark on the implementation of the eHealth strategies, for example, the National eHealth Strategy Toolkit (WHO \& ITU, 2012) and the Nordic eHealth Benchmarking Project (Hyppönen et al., 2015), it will become even more important to understand health sciences students' knowledge of eHealth within their local policy contexts. For example, in Australia, there has been widespread promotion of Personally Controlled Electronic Health Records (PCEHRs) (Australian Government, 2011) in mainstream media, coupled with a high speed national broadband roll-out (Na- 
tional Broadband Network Company, 2015). It is not known whether such initiatives may positively affect the nature of students' knowledge and awareness of eHealth.

In addition to designing curricula that develop students' understanding of eHealth, allied health education should also equip students to be confident in their use of ICT and prepare them to lead eHealth initiatives at workplaces where eHealth adoption is low. Understanding students' current confidence with translating their ICT skills to unfamiliar healthcare contexts is important for developing health curricula.

In light of initiatives to implement eHealth strategies into the workplace, it is now necessary to update knowledge of students' confidence using ICT. Further, current understanding about health sciences students' confidence in using ICT is problematic. Studies examining students' confidence have tended to use self-report scales that ask students to rate their level of confidence using particular tools and their perceived computer skills (Clark et al., 2009; Dahlstrom \& Bischel, 2014; Dahlstrom et al., 2013; Edirippulige et al., 2007). There is a need to investigate students' confidence using ICT for various purposes and within a range of contexts, for example, using spreadsheets and videoconferencing facilities for meetings to explicitly investigate the claim that students are comfortable using ICT for social but not professional health purposes. Measures of confidence can also be strengthened by asking students their perceived training and support needs for effective ICT use in different contexts.

Given that eHealth implementation is becoming a global priority, it is important to investigate health sciences students' preparedness for working in an eHealth-enabled environment and for leading change in healthcare practice where eHealth is under-utilized. Findings regarding factors affecting students' attitudes towards eHealth are published elsewhere (Lam, Nguyen, Lowe, Nagarajan, \& Lincoln, 2014). The aim of this study was to explore students' understanding of eHealth, their use of and confidence in using ICT for personal and professional purposes, confidence and self-efficacy for learning new ICT skills, and perceived training needs. It was hypothesized that students' understanding of eHealth would be limited and reflect only aspects of eHealth they had prior exposure to (e.g., PCEHRs). It was also hypothesized that students would be active and confident ICT users for personal purposes; however students would report low confidence and a need for training in how to use ICT as a health professional.

\section{Research Design}

The cross-sectional survey study reported in this paper was conducted in Semester 2, 2013 as part of a three year longitudinal study of health sciences students' understanding and attitudes towards eHealth. This period was chosen in order to sample students prior to the introduction of an undergraduate and a postgraduate eHealth subject. Both the design and reporting of the study were informed by available survey reporting guidelines (Bennett et al., 2011).

\section{Procedure}

A survey design using convenience sampling was implemented. Ethical approval (2013/552) was granted by the University of Sydney Human Research Ethics Committee. Participants were recruited using written and verbal advertisements at the start of the semester (via the student learning management system, student eNewsletter, and face-to-face in-class invitations). All written invitations contained a link to the online survey available on Survey Monkey. Although participation was anonymous, students could enter their email address at the end of the survey to participate in a draw for a prize. After the winner was determined all email addresses were deleted. The survey was open for seven weeks, commencing week 1 of semester and an email reminder was sent by the lead researcher one week before closing. 


\section{Participants}

A total of 420 students participated in the survey. Participants' ages ranged from 18-56 years (M 22.8 , SD 6.33$)$ and $77.6 \%$ were female $(n=326)$. The majority of participants $(n=301,71.7 \%)$ were undergraduate students (UG), with postgraduate coursework students (PG CW) representing nearly a quarter of the sample $(n=104,24.8 \%)$. A small percentage of students $(n=15,3.6 \%)$ were postgraduate higher degree research students (PG R). The two groups of postgraduate students were combined to form the postgraduate (PG) cohort in subsequent analysis. Based on the number of students enrolled in 2013, this corresponded to a response rate of $10 \%$ of the student cohort.

The sample included representation from a range of UG/PG degrees and disciplines. Bachelor of Health Sciences (a foundation health degree) students comprised $26.8 \%$ of the sample. The remainder of the sample was comprised of students from coursework occupational therapy $(17.9 \%)$, physiotherapy (15.5\%), speech pathology $(13.0 \%)$, nursing $(8.4 \%)$, exercise and sports sciences/exercise physiology $(6.6 \%)$, diagnostic radiography $(6.6 \%)$, and rehabilitation counselling $(0.5 \%)$. Although not part of the Faculty of Health Sciences, students from the Faculty of Nursing who were undertaking a dual degree in Bachelor of Health Sciences and Master of Nursing also completed the survey.

\section{Materials}

An online questionnaire was developed to assess students' understanding of eHealth and their confidence for using technology in health. The survey contained 17 standardised and nonstandardised questions about demographics (including devices owned), understanding of eHealth, attitudes towards eHealth, frequency of engagement with online activities and common software, confidence using ICTs, perceived training needs, and confidence and self-efficacy for learning new ICT skills (see Appendix). Findings regarding factors affecting students' attitudes towards eHealth are published elsewhere (Lam et al., 2014).

\section{Understanding of eHealth}

Students' understanding of eHealth was ascertained by asking them to provide a definition of eHealth. The students were also requested to list 5 ways in which they were aware that eHealth was being used for the provision of healthcare.

\section{Frequency of engagement in online activities and with common software}

Participants were asked to report their frequency of use or engagement with specific online activities such as social networking sites (SNSs), email, video chat, file sharing, virtual activities such as gaming, streaming of music and movies, shopping, information sites including news, weather, entertainment, health and finance, educational research, and real-time communication. Participants indicated their frequency of use of such activities by selecting either "Daily", "1-2 times per week", or "3-4 times per week".

Participants were asked to indicate their frequency of use of software applications such as word processor, presentation, spreadsheet, database, data analysis, video conferencing, audio editing, video editing, and image editing. Students indicated their use of such applications by selecting either "Daily", "1-2 times per week", "3-4 times per week", "Monthly" or "Never". 


\section{Confidence with ICT}

Students' confidence with ICT was examined in three components: (a) confidence and selfefficacy for learning new ICT tools, (b) confidence using a range of commonly available software, and (c) perceived training needs for using these software.

Sixteen items from Hegarty et al. (2010) aimed to measure students' perceived confidence and self-efficacy for learning new ICT skills were used in this study. To examine confidence in learning new ICT skills, the questionnaire presented participants with a number of scenarios where the person would need to learn a new computer technology or online tool. Scenarios varied in the amount and type of support provided (from no support, to instruction manual only, to an expert providing step-by-step instruction). Participants indicated whether they felt "extremely unconfident", "unconfident", "confident", or "extremely confident" in each scenario. To examine selfefficacy, participants were asked to indicate the extent to which a range of reactions to learning new computer technologies or online tools were "like them". The reactions varied in the degree to which the respondent would persist with learning a new tool, the type of support they would seek, and when they would seek this support. The available responses were "extremely unlike me", "unlike me", "like me," and "extremely like me". These responses were grouped into "confident" (confident, extremely confident) and "not confident" (unconfident, extremely unconfident) and "like me" (like me, extremely like me) and "not like me" (unlike me, extremely unlike me) respectively for subsequent descriptive analysis.

Participants were asked to rate their confidence using and need for training for a variety of commonly available software by indicating whether they were "not confident at all", "somewhat not confident", "confident", or "very confident" and whether they "need a lot of training", " need some training", or "don't need training". These included word processing, creating presentations, using spreadsheets, as well as editing files, content sharing, online information gathering, and communication (e.g., email, video conferencing). Responses were grouped into "confident" (confident, very confident) or "not confident" (not confident at all, somewhat not confident) and "need training" (need a lot of training, need some training) or "do not need training" for subsequent analysis.

\section{Analysis}

IBM SPSS (Version 21.0) was used to generate descriptive summaries of the quantitative data for this study. These summaries include counts and percentages where appropriate.

To examine potential effects of demographic variables on students' responses, differences between UG/PG status and gender were also examined. Existing research suggests that the effect of age on ICT skills and ICT self-efficacy is explained by people's age of first use of a computer (i.e., their years of experience with ICT) rather than raw age (Heerwegh, De Wit \& Verhoeven, 2016; Kubiatko \& Vlckova, 2010). As age of first use of ICT (a more meaningful measure than raw age) was not measured in our study and our students' ages fell into a limited range, we did not analyse the effect of age on ICT skills and self-efficacy.

Independent samples t-tests were used to examine if there were significant gender differences for students' confidence and self-efficacy for learning new ICT skills. An alpha level of 0.05 was used for these tests.

Chi-square tests were used to determine if there were associations between (a) gender, and (b) UG and PG students in their confidence and perceived training requirements for the use of commonly available software, their frequency of use of such software, and their frequency of engagement in a list of online activities. Bonferroni adjustment was made when considering significance. Based on this adjustment, any associations with a $p$ value less than 0.002 were considered 
significant. When a significant association was not found, results from both student groups were combined.

Two survey questions explored students' understanding of eHealth: participants' definition of eHealth (Q1), and five ways in which participants were aware eHealth was being used for the provision of healthcare (Q2). Based on the recommendations of Elo and Kyngäs (2008) and Hsieh and Shannon (2005), a simple content analysis was performed to analyze students' responses to these open-ended questions. In the first stage of analysis, a researcher (EP or $\mathrm{MH})$ read each definition (Q1) and use of eHealth (Q2) and then assigned an open code summarizing the key content of the response. For example the response to Q1, "The use of information technologies to increase the efficiency and accuracy of care in the health domain" was assigned an open code of "Use of information technology to improve health care".

Similar codes were grouped together to form main categories, which were each given a descriptive title. For example "Use of information technology to improve health care" and other similar responses (e.g., using electronic resources to help improve healthcare) were grouped under the heading "Improving health service delivery through information technologies". For responses to Q2, open codes were categorized according to whether they reflected either (a) the function of eHealth described, or (b) the type of technology platforms utilized. Not all responses included both a type of function and technology platform; some focused only on the function of eHealth in healthcare management and delivery, others focused only on the type of technology platform utilized.

In the second stage of analysis, three authors (ML, SN, RL) reviewed all coding for Q1, and a second author (EP) reviewed 10\% of the responses to Q2, with any disagreements resolved through consensus (Krippendorff, 2004). Those authors agreed on the illustrative quotes to be included for each category for Q1.

Frequencies of each category of eHealth definition and the number of unique eHealth functions, and eHealth technology platforms described by each student in Q2 were calculated. For instance, in this student's response "delivery of stuttering therapy via Skype" (coded as eHealth function: service delivery; eHealth technology platform: videoconferencing) and "Telephone or video consultations with patients in rural/remote areas" (coded as eHealth function: service delivery; eHealth technology platform: telephone, videoconferencing), was deemed to consist of one unique eHealth function (i.e., service delivery); and two unique technology platforms (i.e., telephone, videoconferencing). The average number of unique eHealth functions and technology platforms described by students across the group was calculated, as well as the frequency of each type of eHealth function and technology platform. In order to investigate patterns in the combination of eHealth functions and technology platforms described, the five most frequently cited eHealth functions were analysed further by calculating the frequencies of each type of associated technology platform.

\section{Results}

This study sought to understand health sciences students' conceptualization of eHealth and their preparedness for engaging with ICT as future health professionals. This section starts by reporting the findings on group differences between UG and PG students and the type of device ownership of the students in the study. This is followed by (a) what students understand by the term, "eHealth"; (b) their online activity and software use; and (c) their confidence using specific technology and learning new ICT skills, and perceived training needs.

Group differences between UG and PG students on all dependent variables were investigated using the Bonferroni adjustment. Only one significant difference between UG and PG students was 
identified and this is reported in the relevant section. All other differences between UG and PG students were not statistically significant.

In relation to device ownership, most students reported owning a laptop/notebook computer and smartphone. Around a third of the participants owned a desktop computer, tablet, game console, or MP3 player. A smaller percentage of students owned MP4 players, portable game consoles, eReaders or a simple phone (other than a smartphone) (Figure 1).

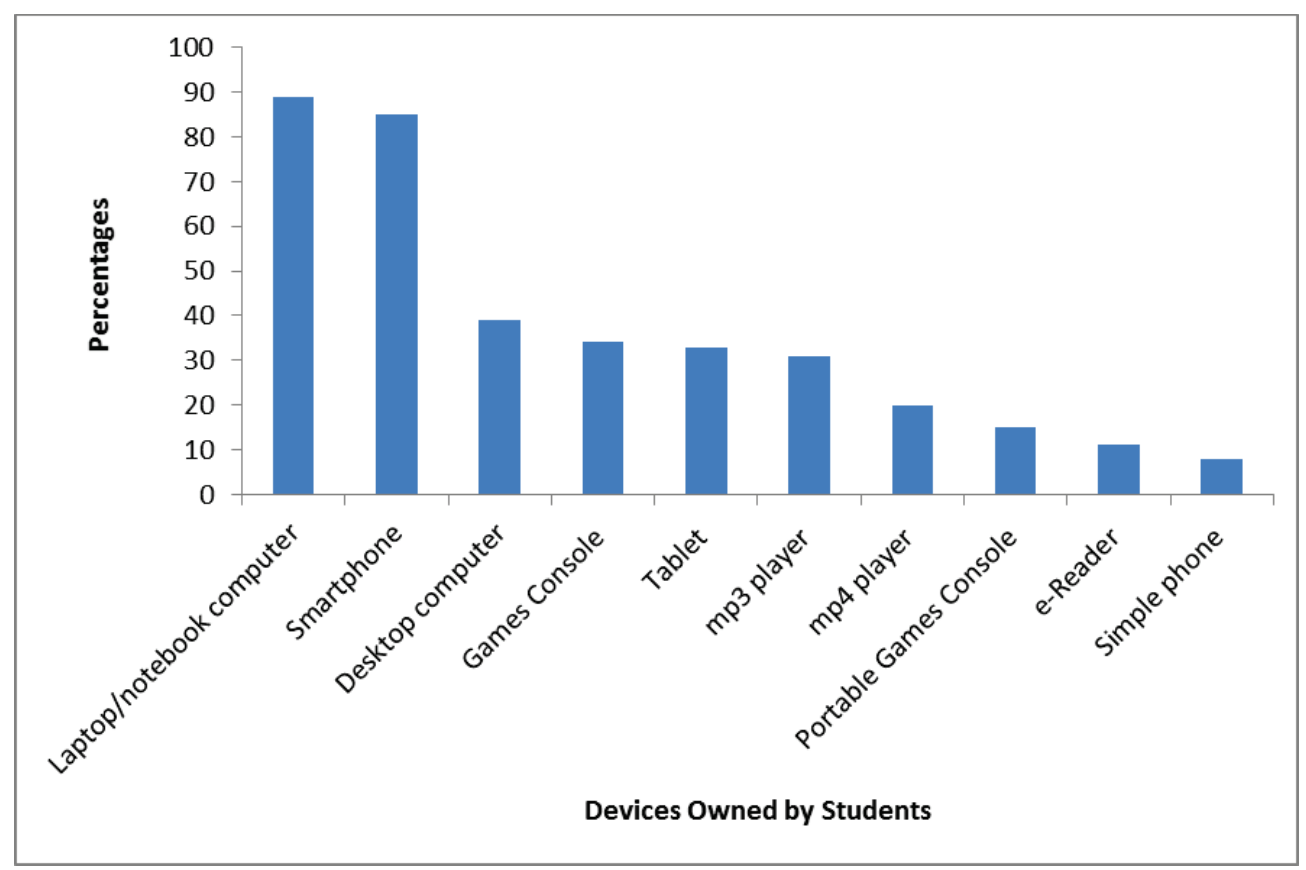

Figure 1. Device Ownership

\section{Understanding of eHealth}

\section{Definitions of eHealth}

Ninety-two percent $(n=390)$ of the total number of students responded to the question "What do you think eHealth is?" Through the content analysis, five main categories emerged: (1) online electronic health records (EHRs); (2) online health resources; (3) delivery of health services; (4) circular definitions; and (5) effects of technology on users' health. An additional "other" category was identified. This category contained sub-groups of responses that could not be categorized elsewhere (unsure, incomplete responses, importance of eHealth, health students' online learning resources and online image and behavior).

The most common definition provided by students (25.6\%) was associated specifically with online EHRs. Student definitions increased in complexity from merely stating "online EHRs" to considerations of EHRs from a consumer's viewpoint for example, "an electronic database for people to monitor their health information". In addition to consumers, other definitions linked online EHRs with health professionals using health service-based terminology, for example, "Medical Records and related patient information on a server - that can be accessed by the patient and the health practitioner". A small number of students extended the definition further by introducing the notion of data sharing through "the use of computer systems to record and transfer data about individuals' health to multiple health care sites". 
The second major category consisted of responses that defined eHealth in relation to online health resources (20.3\% of responses). Specifically, students referred to consumers "accessing Health documents via the internet", and in particular, accessing "Online health advice" and "being informed of your health/health risks via the internet". This included "people diagnosing themselves with the internet". Students also perceived eHealth as a platform used by health service providers to disseminate health resources that educate consumers: "using online sources to inform, educate" and "how online platforms such as social media etc. can help to enhance the wellbeing of people through the dissemination of health related information".

The next most commonly reported definition (19.2\%) focused on using technology to deliver health services. Here, eHealth was the use of technology in healthcare management "the use of technology in the way health is organized, managed and operated" and service provision, "Promoting, diagnosing an [sic] treating health using online technology". Some students emphasized eHealth as an alternative to face-to-face service delivery, for example, "use of technology such as video conferencing or Skype to consult with clients". Further, $4.6 \%$ respondents wrote that eHealth was the use of technology to improve the quality of healthcare and its accessibility: "the use of information technologies to increase the efficiency and accuracy of care in the health domain". This quote demonstrates that for some students, eHealth is a means for overcoming difficulties in accessing health services: "I think e-health is a means for people who find it hard to access a health practitioner [to] be able to get a diagnosis or education on the illness". This is distinct from the idea that eHealth provides alternate modes of service delivery independent of access issues, for example, "use of technology such as video conferencing or Skype to consult with clients".

In contrast to the more detailed and specific definitions of eHealth above, almost one in five students provided largely circular definitions of eHealth. These students rephrased the term as "online health", or "the use of technology in health services". Compared with this group, approximately $5 \%$ of the respondents related eHealth to the effects of technology on users' health. Definitions ranged from more concrete examples associated with ergonomics, "Internet related health. Like time sitting at computer" to broad representations of eHealth as "relating physical and mental health to use of technology - how technology impacts our health". Finally in the 'Other' category, 3.1\% of students reported being unsure about the definition of eHealth. Four students did not define eHealth but instead emphasized their perception of its growing importance, for example, "Will be very important for the health of Australians in the future...". Four responses focused on definitions more associated with student-based learning resources, "An online community where health students can discuss and gain access to information important for their degree", and one student defined eHealth as an "Online image associated with social media".

\section{Uses of eHealth}

Eighty-four percent $(n=358)$ of participants provided 1331 uses of eHealth. Of these responses, 31 could not be analyzed (e.g., non-specific responses, responses that did not describe either a function of eHealth or technology platform, and responses that described rationales for eHealth rather than how it is used) were not considered for further analysis. The remaining 1300 responses from 354 participants were analyzed.

Results suggested that students were aware of a wide range of uses of eHealth and regularly recognized applications for use by both health practitioners and consumers. Students described an average of 2.6 unique functions of eHealth, with comparable results for UG and PG students. The most commonly described function of eHealth was the EHR (referred to in $19.0 \%$ of responses). Uses of eHealth in specific clinical contexts $(18.0 \%)$, provision of consumer health information $(17.3 \%)$, general clinical use $(12.2 \%)$, and service delivery $(10.2 \%)$ were the next most frequently 
described functions of eHealth. Some students provided specific applications for the use of eHealth in service delivery. For instance, 10 speech pathology students ( $18.9 \%$ of all speech pathology students surveyed) referred to telehealth for the delivery of stuttering intervention, such as the Lidcombe Program (Bridgman, Onslow, O’Brian, Jones, \& Block, in press) and the Camperdown Program (Carey et al., 2010).

On the whole, students were less likely to describe specific technology platforms than the function of eHealth applications in their responses. The average number of unique types of technology platforms used in eHealth described by each student was 1.6. Responses ranged from disciplinespecific technical equipment $(13.5 \%$ of responses) and information systems $(9.2 \%)$ to readily available, everyday platforms such as mobile technologies $(8.8 \%)$, websites $(7.7 \%)$, videoconferencing $(4.1 \%)$ and social media $(2.8 \%)$.

The five most frequently described functions of eHealth were further analyzed to determine the associated types of technology described by students. In the majority $(82.6 \%)$ of responses that identified EHRs as a function, EHRs were described without reference to a specific technology platform. For the $95.3 \%$ of responses that did identify a technology platform for EHRs they were typically referred to as information systems. Descriptions of these information systems at times included reference to specific hospital information systems, such as "use of computer to compile Cerner ${ }^{\circledR}$ notes". Other responses were more general, referring to databases to manage patient files.

Descriptions of uses of eHealth in specific clinical contexts tended to include direct reference to discipline-specific technical equipment (61.5\% of responses), e.g., x-ray machines for diagnosis, assistive devices for managing communication disorders, and the use of robotics in surgery. Everyday technology, such as mobile technology $(10.1 \%)$ and gaming devices $(5.7 \%)$, were less frequently reported. Information systems such as picturing archiving and communication systems (PACS) or radiology information systems (RIS) were described as technology platforms for specific clinical applications only by PG students $(22.8 \%)$.

In contrast to descriptions of the uses of eHealth in specific clinical contexts, descriptions related to consumer health information were more likely to include references to everyday technology, including websites (32.7\%), mobile technology (16.1\%), and social media $(11.2 \%)$. Those descriptions encompassed a range of technology platforms, including telecommunications, videoconferencing, and gaming.

Email was most commonly (11.3\%) referred to for use in general clinical tasks. Similarly, the function of eHealth in service delivery was most commonly associated with videoconferencing $(28.6 \%)$, and to a lesser extent, delivery of services via telephone $(7.5 \%)$.

\section{Students' online activity and software use}

Participants reported on their engagement with online activities and use of commonly available software. Participants who reported engagement with online activities and software use were asked follow-on questions regarding their frequency of use. As the numbers of students reporting engagement with each online activity or software varied, the denominators for each variable varied accordingly. The frequencies and percentages for each variable are therefore provided as summary statistics.

\section{Online activity}

Seventy-seven percent $(n=323)$ of participants responded to the question asking about their use of online activities including SNSs, blogs, file sharing, online collaboration tools, and gaming and virtual environments. The percentages of students engaged in the various online activities are presented in Figure 2. 


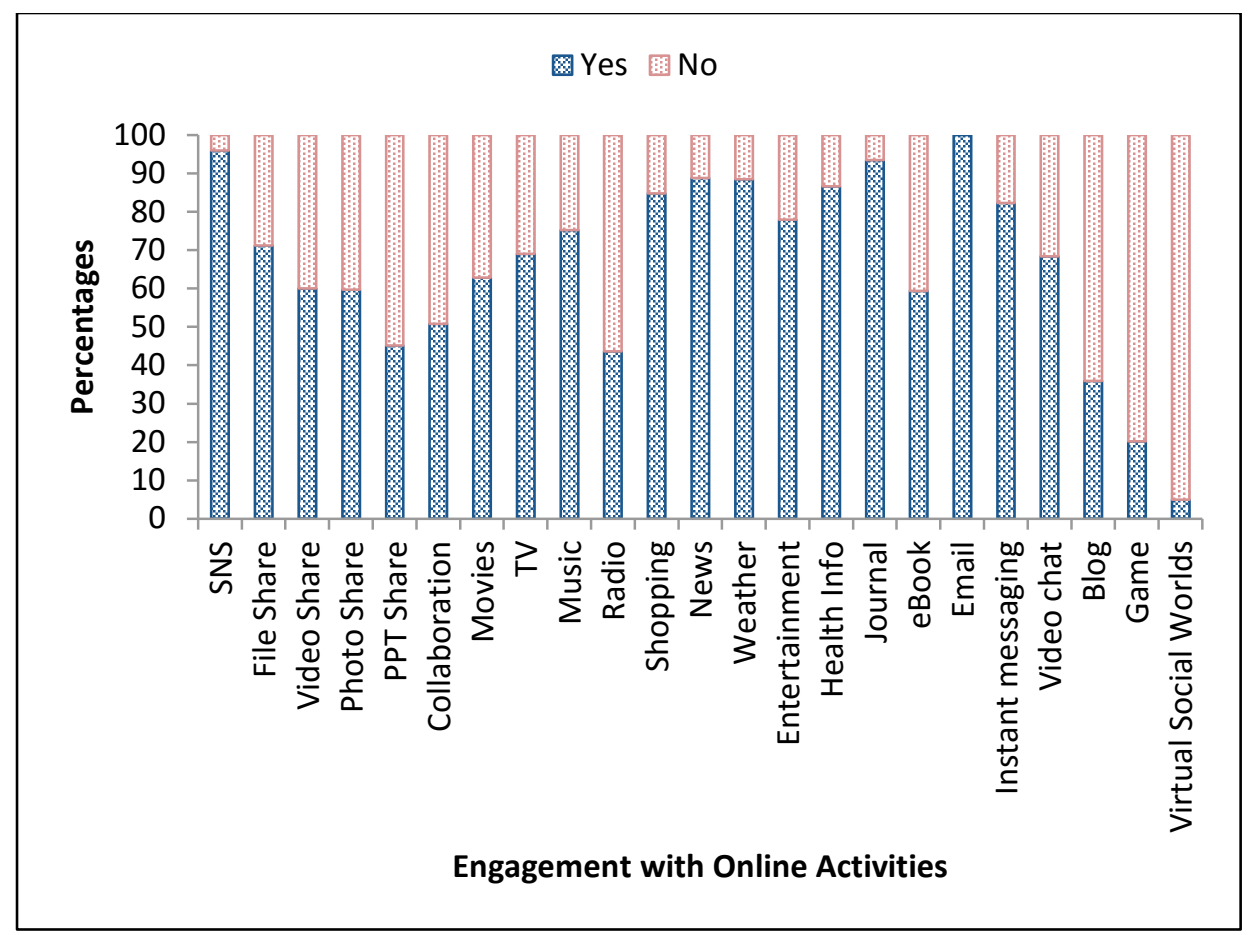

Figure 2. Engagement with online activities

Thirteen students (4\%) reported that they never use SNSs. Around half of the students who used SNSs used this medium for personal use only. Half reported both personal and educational use. Only a small percentage used SNSs for educational use only. The frequency with which participants reported engaging with SNSs for personal and/or educational use is presented in Table 1.

Table 1. Frequencies of SNS engagement

\begin{tabular}{|c|c|c|c|c|}
\hline & \multicolumn{4}{|c|}{ SNS Use (number, percentage) } \\
\hline & $\begin{array}{c}\text { Personal use only } \\
(\mathbf{n}=\mathbf{1 5 3}, \mathbf{4 7 \%})\end{array}$ & $\begin{array}{c}\text { Educational use } \\
\text { only } \\
(\mathbf{n}=\mathbf{6 , 2 \%})\end{array}$ & $\begin{array}{c}\text { Both personal and educational use } \\
(\mathbf{n}=\mathbf{1 5 1}, \mathbf{4 7} \%)\end{array}$ \\
\hline Frequency of Use & & & Personal & Educational \\
\hline 1 - 2 times a week & $11 \%$ & $67 \%$ & $6 \%$ & $17 \%$ \\
\hline 3 - 4 times a week & $6 \%$ & $33 \%$ & $9 \%$ & $5 \%$ \\
\hline Everyday & $83 \%$ & $0 \%$ & $86 \%$ & $2 \%$ \\
\hline
\end{tabular}

The frequency with which participants reported engaging in different online activities is presented in Tables $2 \mathrm{a}$ and $2 \mathrm{~b}$. The majority of students reported using email and instant messaging on a daily basis. Around two-thirds of the students reported to use online entertainment and around half reported to use online information sources a couple of times per week. In contrast, around half of the students reported to access information about the weather on a daily basis. Around two thirds of the students reported to engage with blogs and online gaming at least a couple of times per week. 
Table 2a. Frequencies of online activities engagement

\begin{tabular}{|c|c|c|c|c|c|c|c|c|}
\hline & \multicolumn{8}{|c|}{ Online Activity Type (number, percentage) - Content sharing } \\
\hline Frequency of Use & $\begin{array}{c}\text { File } \\
(n=230 \\
71 \%)\end{array}$ & \multicolumn{2}{|c|}{$\begin{array}{c}\text { Video } \\
(n=196, \\
61 \%)\end{array}$} & \multicolumn{2}{|c|}{$\begin{array}{c}\text { Photo } \\
(n=194, \\
60 \%)\end{array}$} & \multicolumn{2}{|c|}{$\begin{array}{c}\text { PPT } \\
(n=148, \\
46 \%)\end{array}$} & $\begin{array}{l}\text { Collaboration } \\
\qquad \begin{array}{c}n=164 \\
51 \%)\end{array}\end{array}$ \\
\hline 1 - 2 times a week & $74 \%$ & \multicolumn{2}{|c|}{$63 \%$} & \multicolumn{2}{|c|}{$56 \%$} & \multicolumn{2}{|c|}{$91 \%$} & $72 \%$ \\
\hline 3 - 4 times a week & $15 \%$ & \multicolumn{2}{|c|}{$15 \%$} & \multicolumn{2}{|c|}{$19 \%$} & \multicolumn{2}{|c|}{$7 \%$} & $18 \%$ \\
\hline \multirow[t]{2}{*}{ Everyday } & $10 \%$ & \multicolumn{2}{|c|}{$22 \%$} & \multicolumn{2}{|c|}{$26 \%$} & \multicolumn{2}{|c|}{$2 \%$} & $10 \%$ \\
\hline & \multicolumn{8}{|c|}{ Online Activity Type (number, percentage) - Online entertainment } \\
\hline Frequency of Use & $\begin{array}{c}\text { Movies } \\
(n=207, \\
64 \%)\end{array}$ & \multicolumn{2}{|c|}{$\begin{array}{c}\text { TV } \\
(n=222, \\
69 \%)\end{array}$} & \multicolumn{2}{|c|}{$\begin{array}{c}\text { Music } \\
(n=242 \\
75 \%)\end{array}$} & \multicolumn{2}{|c|}{$\begin{array}{c}\text { Radio } \\
(n=141 \\
44 \%)\end{array}$} & $\begin{array}{c}\text { Shopping } \\
(n=273, \\
84 \%)\end{array}$ \\
\hline 1 - 2 times a week & $72 \%$ & \multicolumn{2}{|c|}{$67 \%$} & \multicolumn{2}{|c|}{$48 \%$} & \multicolumn{2}{|c|}{$67 \%$} & $84 \%$ \\
\hline 3 - 4 times a week & $17 \%$ & \multicolumn{2}{|c|}{$19 \%$} & \multicolumn{2}{|c|}{$23 \%$} & \multicolumn{2}{|c|}{$13 \%$} & $13 \%$ \\
\hline \multirow[t]{2}{*}{ Everyday } & $11 \%$ & \multicolumn{2}{|c|}{$14 \%$} & \multicolumn{2}{|c|}{$29 \%$} & \multicolumn{2}{|c|}{$19 \%$} & $3 \%$ \\
\hline & \multicolumn{8}{|c|}{ Online Activity Type (number, percentage) - Online information } \\
\hline Frequency of Use & $\begin{array}{c}\text { News } \\
(n=286, \\
89 \%)\end{array}$ & $\begin{array}{c}\text { Weather } \\
(n=285, \\
88 \%)\end{array}$ & & $\begin{array}{l}\text { tain- } \\
\text { nt } \\
251\end{array}$ & & & $\begin{array}{c}\text { Journal } \\
(n=301 \\
93 \%)\end{array}$ & $\begin{array}{c}\text { eBook } \\
(n=191 \\
59 \%)\end{array}$ \\
\hline 1 - 2 times a week & $43 \%$ & $28 \%$ & & & & & $61 \%$ & $77 \%$ \\
\hline 3 - 4 times a week & $20 \%$ & $22 \%$ & & & & & $26 \%$ & $17 \%$ \\
\hline \multirow[t]{2}{*}{ Everyday } & $37 \%$ & $51 \%$ & & & & & $13 \%$ & $6 \%$ \\
\hline & \multicolumn{8}{|c|}{ Online Activity Type (number, percentage) - Communication } \\
\hline Frequency of Use & $\begin{array}{r}\text { Em } \\
(n=323\end{array}$ & $00 \%)$ & & $\begin{array}{l}\tan t \\
n=26\end{array}$ & $\%$ & & $\begin{array}{r}\text { Vic } \\
(n=2\end{array}$ & $\begin{array}{l}\text { leo chat } \\
220,68 \%)\end{array}$ \\
\hline 1 - 2 times a week & 2 & & & & & & & $80 \%$ \\
\hline 3 - 4 times a week & 8 & & & & & & & $12 \%$ \\
\hline Everyday & & & & & & & & $9 \%$ \\
\hline
\end{tabular}


Table $2 \mathrm{~b}$. Frequencies of other online activities engagement

\begin{tabular}{|c|c|c|c|}
\hline & \multicolumn{2}{|c|}{ Online Activity Type (number, percentage) - Others } \\
\hline Frequency of Use & $\begin{array}{c}\text { Blog } \\
(\mathbf{n}=\mathbf{1 1 8}, \mathbf{3 7} \%)\end{array}$ & $\begin{array}{c}\text { Gaming } \\
(\mathbf{n}=\mathbf{6 5}, \mathbf{2 0} \%)\end{array}$ & $\begin{array}{c}\text { Virtual social worlds } \\
(\boldsymbol{n}=\mathbf{1 6}, \mathbf{5} \%)\end{array}$ \\
\hline $1-2$ times a week & $74 \%$ & $68 \%$ & $75 \%$ \\
\hline $3-4$ times a week & $13 \%$ & $15 \%$ & $6 \%$ \\
\hline Everyday & $14 \%$ & $17 \%$ & $19 \%$ \\
\hline
\end{tabular}

\section{Software use}

A total of 354 students answered this question. Most students reported using applications such as word processing, presentation, spreadsheets, databases, and image editing software. In comparison, fewer students reported use of application software for video conferencing, audio and video editing purposes. The percentage of participants who reported to use various software applications and their reported frequency of use are presented in Table 3. Not surprisingly word processing software was reported to be used on a daily basis by over half the sample while other software applications were used less frequently.

Table 3. Software use

\begin{tabular}{|c|c|c|c|c|c|c|}
\hline & \multicolumn{6}{|c|}{ Software (number, percentage) } \\
\hline Frequency of Use & $\begin{array}{l}\text { Word processing } \\
(n=352,99 \%)\end{array}$ & $\begin{array}{l}\text { Presentation } \\
(n=333,95 \%)\end{array}$ & & $\begin{array}{l}\text { eadsheet } \\
=243 \text {, } \\
\text { o) }\end{array}$ & $\begin{array}{l}\text { Database } \\
(\mathrm{n}=\mathbf{2 0 2}, \\
\mathbf{5 7 \%})\end{array}$ & $\begin{array}{l}\text { Data analysis } \\
(n=159, \mathbf{4 5} \%)\end{array}$ \\
\hline Monthly & $4 \%$ & $59 \%$ & & $52 \%$ & $43 \%$ & $59 \%$ \\
\hline 1 - 2 times a week & $19 \%$ & $25 \%$ & & $34 \%$ & $29 \%$ & $26 \%$ \\
\hline 3 - 4 times a week & $18 \%$ & $7 \%$ & & $7 \%$ & $15 \%$ & $8 \%$ \\
\hline \multirow[t]{2}{*}{ Everyday } & $59 \%$ & $9 \%$ & & $7 \%$ & $13 \%$ & $8 \%$ \\
\hline & \multicolumn{6}{|c|}{ Software (number, percentage) } \\
\hline Frequency of Use & $\begin{array}{l}\text { Video confer- } \\
\text { encing software } \\
(n=\mathbf{1 2 9}, \mathbf{3 6} \%)\end{array}$ & \multicolumn{2}{|c|}{$\begin{array}{c}\text { Audio editing } \\
\text { software } \\
(n=89,25 \%)\end{array}$} & \multicolumn{2}{|c|}{$\begin{array}{c}\text { Video editing } \\
\text { software } \\
(n=103,29 \%)\end{array}$} & $\begin{array}{c}\text { Image editing } \\
\text { software } \\
(n=215,61 \%)\end{array}$ \\
\hline Monthly & $60 \%$ & \multicolumn{2}{|l|}{$78 \%$} & \multicolumn{2}{|c|}{$84 \%$} & $61 \%$ \\
\hline $1-2$ times a week & $28 \%$ & \multicolumn{2}{|l|}{$15 \%$} & \multicolumn{2}{|c|}{$11 \%$} & $29 \%$ \\
\hline 3 - 4 times a week & $3 \%$ & \multicolumn{2}{|l|}{$4 \%$} & \multicolumn{2}{|c|}{$2 \%$} & $3 \%$ \\
\hline Everyday & $9 \%$ & \multicolumn{2}{|l|}{$3 \%$} & \multicolumn{2}{|c|}{$3 \%$} & $7 \%$ \\
\hline
\end{tabular}




\section{Confidence with ICT}

A total of 356 students answered this question.

\section{Confidence and self-efficacy in learning new ICT tools}

Using the scoring system reported in Hegarty et al. (2010), these two scales showed good internal consistency as measured by Cronbach's alpha ( $\alpha=0.76$ for both scales). Students reported confidence learning new ICT skills if support was provided. The majority of students reported they would be confident learning a new ICT skill if sufficient time (endorsed by $98 \%$ of participants) or human support (99\%) was provided. Students were also motivated to solve ICT problems. When asked about their responses to IT problems, most students reported being persistent $(80 \%)$, putting in effort to work through issues (89\%), and spending extra time if necessary $(90 \%)$. Students were less likely to endorse statements that suggested they would give up quickly (12\%) or doubted their ability to solve ICT problems (28\%).

There was a significant gender difference in students' reported confidence $\left(\mathrm{T}_{354}=2.16, \mathrm{p}=0.03\right)$ and self-efficacy for learning new ICT skills $\left(\mathrm{T}_{354}=2.80, \mathrm{p}=0.005\right)$. Males reported significantly higher scores on both confidence and self-efficacy for learning new ICT skills [mean difference of confidence $=0.68(95 \% \mathrm{CI}=0.06,1.30)$; mean difference of self-efficacy $=1.30(95 \% \mathrm{CI}=0.39$, 2.21)].

\section{Confidence in using commonly available software}

Of all the students who completed the survey, over $90 \%$ of respondents reported to be confident using word processing software, preparing presentation slides, communicating through email and messaging, and sharing word documents. Rates of confidence for creating (56\%) and managing (39\%) spreadsheets was not as high. Over $75 \%$ of respondents reported to be confident sharing multiple types of media (e.g., video, music, presentations, and photos), searching through professional or evidence base databases, using video chat (social), and with social media management.

Areas where over $90 \%$ of respondents were not confident included having and using specialized technical skills (e.g., query database using SQL syntax, app development, and programming). More than three quarters of respondents rated themselves as not confident with website development, creating a database, and using database software.

Interestingly, students were confident using video chat (85\%) but comparatively less confident using video conferencing for professional purposes (52\%). A similar pattern was observed for using social media (75\%) and online reputation management $(43 \%)$.

Overall, there were no significant differences observed between male and female students for their ratings of confidence for the majority of ICT tools and software. However, the PG group rated themselves as significantly more confident than UG students for 'creating a database' $(\mathrm{PG}=27 \%, \mathrm{UG}=12 \%, \mathrm{p}=0.001)$.

\section{Perceived training required for using commonly available software}

Overall, students' perceived need for training was congruent with a lack of confidence with specific software and technology applications (see Figure 3). Over $90 \%$ of students indicated a need for training in specialized technical skills such as database use, app development, and programming. Other areas where over $75 \%$ of the group reported the need for training included spreadsheet creation and data management, setting up video conferencing, editing of audio and video files, and online reputation management. Emailing and messaging were least frequently endorsed by students as skills they required training to use. 
Despite this congruence, there were some divergent patterns. For example, although $95 \%$ of participants reported feeling confident preparing presentation slides or sharing word documents (90\%), at least one quarter of the group still indicated a need for training in these areas. At least three quarters of students were confident in social media management and use of online, professional databases. However, 50\% still reported training needs in this area. On average, $16 \%$ more students rated a need for training than students who indicated they were not confident.

In terms of perceived training needs, no significant differences were observed between UG and PG participants. There were no significant differences observed between males and females for their perceived need for training on the majority ( 25 of 28) ICT tools and software. Significantly more female students reported the need for training in setting up video conferencing (male $=61 \%$, female $=82 \%, p=0.001)$, online reputation management (male $=61 \%$, female $=80 \%, p=0.001)$ and website development (male $=87 \%$, female $=97 \%, \mathrm{p}=0.001$ ).

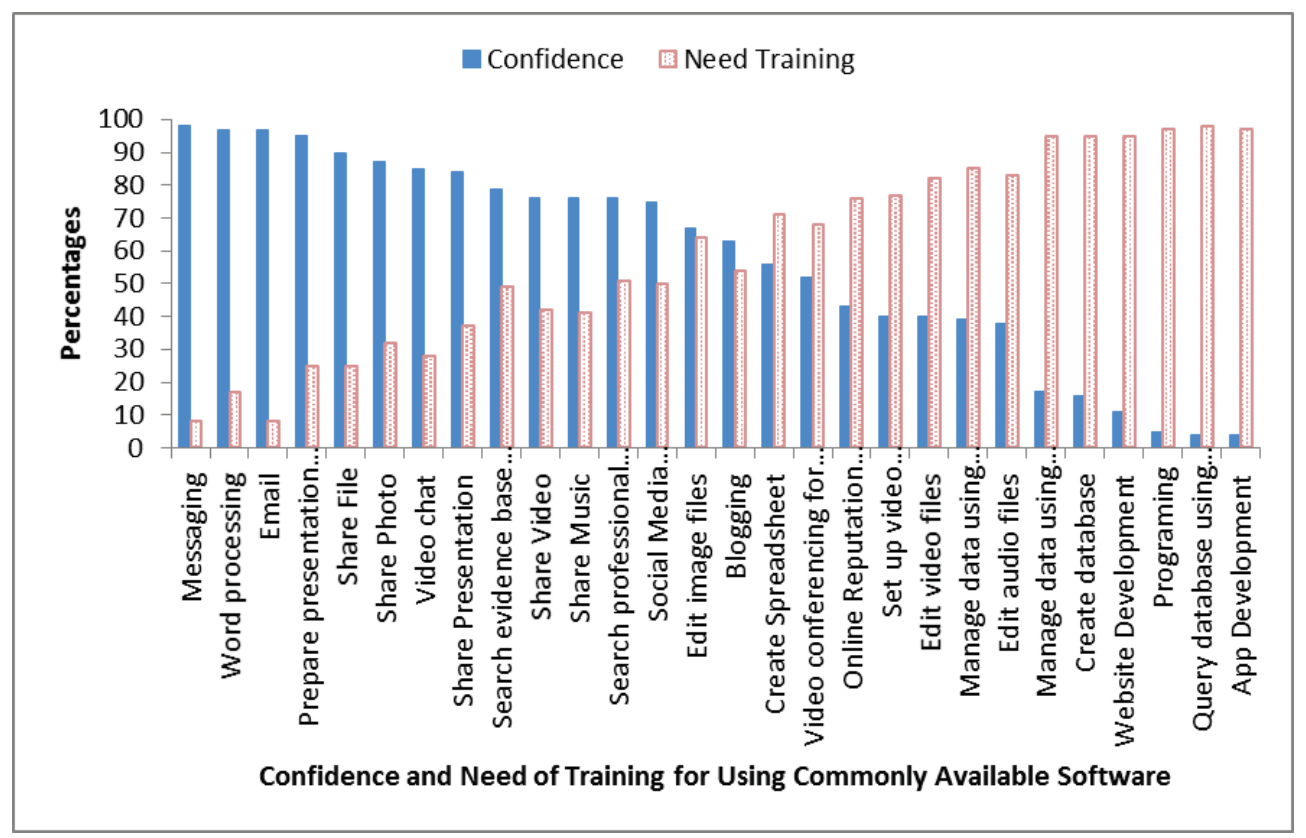

Figure 3. ICT skill confidence and perceived training needs

\section{Discussion}

In this study, health sciences students reported that they regularly engage in a wide range of online activities and use commonly available software. Consistent with our hypothesis, most students' understanding of eHealth is uncertain or limited, demonstrated by vague or circular definitions of eHealth. This could, at least in part, explain students' lack of confidence in transferring their ICT skills to a healthcare context despite reporting confidence in using commonly available technology, learning new ICT skills and solving ICT problems if provided with sufficient support. So, as hypothesized, while students demonstrated the technical skills that would potentially enable them to engage in eHealth, they displayed a lack of understanding how these skills could be applied to professional health contexts.

An examination of gender differences showed that although male students reported greater confidence in, and self-efficacy for, learning new ICT skills, there were no significant differences in students' ratings of their confidence for using most ICT tools. The only exceptions were that a greater proportion of female compared to male students reported needing training in videoconferencing, online reputation management, and website development. Consistent with previous research (Heerwegh et al., 2016), these findings suggest the gender divide in ICT confidence may 
be diminishing while highlighting a need for more nuanced understanding of differences in approaches to specific ICT tools and tasks by different genders.

\section{Students' Understanding of eHealth}

Consistent with previous research with nursing students (Clark et al., 2009; Edirippulige et al., 2007-2008) and nurse practitioners (Eley et al., 2009), the majority of health sciences students in this study demonstrated a limited or unclear understanding of eHealth. The students' limited understanding in this study appears to be informed by their direct experiences as health consumers. For example, when asked to define eHealth and describe how technology is used in healthcare, EHRs was the dominant response. One potential explanation for this is that at the time of the survey, the Australian Government had introduced PCEHRs. To encourage Australians to opt into this system, there was a large campaign using mainstream media to raise awareness about the benefits of EHRs. Exposure to this campaign could have influenced students' understanding of this aspect of eHealth.

Similarly, students' definitions of eHealth appeared to reflect their knowledge of specific, evidence-based examples of eHealth they had encountered in their university studies. For example, speech pathology students, who learn about the efficacy of telehealth delivery of interventions for stuttering within their course, frequently referred to this mode of delivery for the Lidcombe Program (Bridgman et al., in press) and the Camperdown Program (Carey et al., 2010). Students also tended to equate functions of eHealth with specialist software and equipment, such as imaging technology and robotics in surgery, rather than involving the use of familiar, everyday technologies such as mobile devices and social media. Instead, students generally associated everyday technologies, not with specific healthcare applications used by health professionals, but with consumers accessing information and monitoring their own health. These results suggest students' understanding of eHealth is formed through their direct exposure to and interaction with eHealth concepts, either as a student or consumer. Moreover, the assumption that students are eHealthready because they are already competent users of ICT (i.e., the digital native myth; Prensky, 2001), is not supported by these findings. Such conclusions appeared to apply to all health sciences students, including PG students.

Minimal differences were observed between UG and PG students' knowledge, skills, and confidence with ICTs and in their understandings of eHealth. Despite the multiple statistical comparisons conducted, only one significant difference between the groups was found. Post graduate students reported to be more confident than UG students for creating databases. Further, in their open-ended responses, PG students were more likely to demonstrate knowledge of specific information systems (e.g., PACS, RIS), whereas UG students' descriptions of information systems were more often generic in nature. Those differences could be due to PG students having prior experience working within healthcare contexts and consequently greater exposure to particular ICTs such as databases and health information systems. Overall the results of this study suggest both UG and PG students may benefit from similar approaches to learning opportunities that enhance students' understanding of eHealth, and how to transfer existing skills and knowledge to professional healthcare roles.

\section{Students are Confident with ICT, not with eHealth}

Students' uncertainty about using technology in healthcare contexts, despite being familiar with and skilled using ICTs in everyday situations, may reflect their limited exposure to eHealth (Dattakumar et al., 2012) in their university studies. In addition, students appeared to lack an understanding of eHealth and confidence in their ability to transfer their existing ICT knowledge and skills to their professional roles. For instance, students generally reported to be confident using video chat, but were not confident using the same technology within a professional context. 
Students' perceived training needs did not appear to be related specifically to technology operation, but rather, in understanding the appropriate use of the technology within a professional health setting. Further, support for this was observed by the close alignment of students' perceived training needs with their confidence ratings.

Students' perception of eHealth as involving specialist technology, rather than novel use of everyday technology, could also explain low confidence levels in their ability to engage with eHealth. Without a clear understanding of the legitimate use of everyday technologies and software in professional healthcare settings, it is not surprising students may underestimate the relevance and value of their existing ICT skills and knowledge. Exposure to a wider range of eHealth applications using common software and technologies (e.g., mobile technologies, social media, file sharing) may also need to be paired with learning activities that support students to identify and recognize their existing skill sets and competencies related to ICT.

Students' apparent difficulty with transferring existing ICT knowledge and skill sets to novel contexts is consistent with research into the use of ICT for learning. Students own and regularly use numerous Internet-enabled devices, both fixed and mobile (Kennedy, Judd, Churchward, Gray, \& Krause, 2008). They report confidence in knowing how to use these technologies (Dahlstrom et al., 2013). However, students require explicit training and scaffolding to understand how to transfer their skills with ICT for social purposes to the higher education learning context. The students in this study appear to know how to use the tools and are confident learning new skills, but require specific learning opportunities that enable the transfer of skills to different contexts for use.

\section{Gender and ICT Knowledge, Skills and Confidence}

Although male students in this study reported greater confidence using ICT and self-efficacy for learning new ICT skills in standardized survey tools, no gender differences were observed for students' reported confidence and perceived training needs for using a majority of specific ICT tools. These include editing and sharing files, using databases and spreadsheets, presentation and word processing software as well as common online communication tools such as email and messaging. However, a greater proportion of female students stated they required training for videoconferencing, online reputation management, and website development.

The finding from this study that male students reported greater confidence for learning new technology skills is consistent with previous research. Males tend to report greater self-efficacy for learning in general (see Huang, 2012 for a meta-analysis of research investigating gender differences in academic self-efficacy) as well as greater confidence in acquiring new ICT skills in particular (Ong \& Lai, 2006). That there are no reported gender differences in students' confidence for using specific technology is also in line with research suggesting the gender divide in ICT attitudes and competency is diminishing (Heerwegh et al., 2016). Padilla-Meléndez, del AguilaObra and Garrido-Moreno (2013) found no differences between male and female students on the perceived ease of use of an eLearning tool. Interestingly, in a study examining students' perceptions of the masculinity or femininity of ICT skills, Kvansky, Joshi, and Trauth (2011) found there were a set of skills identified as gender neutral. The pervasiveness of ICT in everyday life increases students' exposure to ICT as well as their opportunity to observe females engaging with technology. This process may serve to reduce the masculinity stereotypes previously associated with technology use.

Our findings also suggest a need for a more nuanced examination of gender differences; a greater proportion of female students compared to male students reported they needed more training for videoconferencing, online reputation management, and website development. This could be a reflection of different social reactions to men and women's online behavior. For instance women may feel pressure to maintain a particular image or reputation online compared to men. Further, 
students' attitudes regarding the perceived masculinity of specific tools and their exposure to or experience with these tools may play a role. Future research should consider exploring these relationships in greater detail.

\section{Implications for eHealth Teaching}

Students in this study reported an open-mindedness and positive attitude towards learning about new technologies and software. Most indicated persistence with learning, stating they would work through an ICT problem if provided with sufficient time. Students therefore seem to understand they will come across new things, recognizing (a) they need support and (b) this support can come in the form of an experienced person or more time. Our results suggest eHealth education for health sciences students should provide students with sufficient time to work through new ICT problems and/or involve guided support by an individual familiar with the ICT system or its application in health contexts.

The findings from this study have been used to inform eHealth teaching at our university. There is a faculty-wide initiative to increase access to eHealth learning experiences. eHealth electives are being rolled out to all UG and PG degrees. The curriculum for these electives includes interviews with health professionals using eHealth in a range of practice settings to broaden student understanding of eHealth. There is greater focus on how and why technology is used for health, including practical role-play sessions to support students' eHealth confidence and skill development. This is in contrast to previous iterations of the subjects which focused on what technology was used in different situations. Our next step will be to identify if and how eHealth is embedded into other subjects (outside the electives). Integrating eHealth into core units of study will enhance perceived relevance of eHealth for students' future practice. Strategies for supporting teachers in this process will also be identified, developed further, and implemented.

In addition to identifying eHealth learning needs of health sciences students, our findings may also be used to enhance learning and teaching practices for increased student engagement. For example, students report high use of virtual worlds. The use of virtual worlds is emerging in higher education (Molka-Danielsen \& Balandin, 2011) as well as in healthcare contexts, for example, the use of virtual worlds for people with Motor Neurone Disease (Brown-Johnson, Berrean, \& Cataldo, 2015) or communication impairment following stroke (EVA, 2015). These results suggest virtual worlds could also be used more extensively to engage students in eHealth.

As has been demonstrated by Jones, Ramanau, Cross, and Healing (2010) with university students, our study uncovered a small group of students who reported no use of common technology and software, such as word processing, presentation software and SNSs. It is possible the suggested approaches designed to support the skills and confidence of the majority of students to engage in eHealth may not be sufficient to support the specific needs of this sub-group of students. Instead, teaching and learning strategies may need to be supplemented, or modified, in order to build students' familiarity and skill level with common technology, before they can be expected to apply ICT knowledge and skills to the professional health workplace.

\section{Limitations}

When interpreting the results from this study some limitations must be considered. Firstly, as data collection occurred via an online survey, the sample may have been biased towards students who are already engaged with technology and therefore more likely to demonstrate strong skills and confidence with ICTs. In addition, the participants were drawn from a convenience sample consisting of one student cohort in a single university. Further, only $10 \%$ of the total number of enrolled students in 2013 completed the survey. The following contextual factors about the institution could have impacted on the students responses: the research intensive nature of the institu- 
tion, being a large Health Sciences faculty located at a satellite campus, enrolment of students who satisfy high entry requirements, availability of online learning and the introduction of eHealth units of study, and gender bias associated with the health science professions (i.e., cohorts with a much higher proportion of females compared with males).

Future studies should consider sampling from several institutions and across different faculties where there may be more male students to determine the generalizability of the results. Secondly, the study explored students' perceived rather than actual ICT skills. Future studies should also consider using other methods for data collection, such as in-class surveys to increase the response rate, and standardized assessments of students' actual ICT skills.

\section{Conclusions / Recommendations}

This study adds important insights to the understanding of the preparedness of health sciences students to engage in eHealth in their future clinical roles. Health professional educational curricula are able to build on a strong foundation of students' existing skills and familiarity with ICTs, and may capitalize on students' willingness to learn about technology. Yet, there are several challenges faced by educators. These include supporting students to see the potential for ICT use in their professional health workplace, identifying and recognising students' current knowledge and skills, facilitating the transfer of students' existing skills to other contexts such as professional practice, and being able to evaluate the effectiveness of eHealth solutions in particular healthcare contexts.

\section{References}

Australian Government. (2011). Bringing the PCEHR to life. Retrieved from https://www.youtube.com/watch?v=3IOoUMwSGMI

Australian Government, Department of Health. (2012). National e-health strategy. Retrieved from http://www.health.gov.au/internet/main/publishing.nsf/Content/National+Ehealth+Strategy

Bennett, C., Khangura, S., Brehaut, J. C., Graham, I. D., Moher, D., Potter, B. K., \& Grimshaw, J. M. (2011). Reporting guidelines for survey research: An analysis of published guidance and reporting practices. PLoS Med, 8(8): e1001069. doi:10.1371/journal.pmed.1001069

Bridgman, K., Onslow, M., O'Brian, S., Jones, M., \& Block, S. (in press). Lidcombe Program webcam treatment for early stuttering: A randomized controlled trial. Journal of Speech, Language and Hearing Research.

Brown, C., \& Czerniewicz, L. (2010). Debunking the 'digital native': Beyond digital apartheid, towards digital democracy. Journal of Computer Assisted Learning, 26, 357-369. doi:10.1111/j.13652729.2010.00369.x

Brown-Johnson, C. G., Berrean, B., \& Cataldo, J. K. (2015). Development and usability evaluation of the mHealth Tool for Lung Cancer (mHealth TLC): A virtual world health game for lung cancer patients. Patient Education and Counselling, 98, 506-511. doi:10.1016/j.pec.2014.12.006

Carey, B., O'Brian, S., Onslow, M., Block, S., Jones, M., \& Packman, A. (2010). Randomized controlled non-inferiority trial of a telehealth treatment for chronic stuttering: The Camperdown Program. International Journal of Language \& Communication Disorders, 45, 108-120. doi:10.3109/13682820902763944

Chedid, R., Dew, A., \& Veitch, C. (2013). Barriers to the use of information and communication technology by occupational therapists working in a rural area of New South Wales, Australia. Australian Occupational Therapy Journal, 60, 197-205. doi:10.1111/1440-1630.12016

Clark, J., Baker, B., \& Baker, D. (2009). Getting eHealth into basic nursing education: Report of the RCN information in nursing project. Studies in Health Technology and Informatics, 146, 534-539. 
Dahlstrom, E., \& Bichsel, J. (2014). ECAR study of undergraduate students and information technology, 2014 (Research Report). Louisville, CO: EDUCAUSE Center for Analysis and Research. Retrieved from https://net.educause.edu/ir/library/pdf/ss14/ERS1406.pdf

Dahlstrom, E., Walker, J. D., \& Dziuban, C. (2013). ECAR study of undergraduate students and information technology, 2013 (Research Report). Louisville, CO: EDUCAUSE Center for Analysis and Research. Retrieved from https://net.educause.edu/ir/library/pdf/ERS1302/ERS1302.pdf

Dattakumar, A., Gray, K., Henderson, K. B., Maeder, A., \& Chenery, H. (2012). We are not educating the future clinical health professional workforce adequately for e-health competence: Findings of an Australian study. Studies in Health Technology and Informatics, 178, 33-38.

Department of Health and Ageing. (2011). The eHealth Readiness of Australia's allied health sector. Retrieved from http://www.health.gov.au/internet/publications/publishing.nsf/Content/ehealth-readinessallied-toc/\$FILE/Allied\%20Health\%20ehealth\%20readiness\%20survey\%20report.pdf

Edirippulige, S., Marasinghe, R. B., Smith A.C., Fujisawa Y., Herath, W. B., . . . Wootton, R. (2007). Medical students' knowledge and perceptions of e-health: Results of a study in Sri Lanka. Studies in Health Technology and Informatics, 129(Pt 2):1406-1409.

Edirippulige, S., Smith, A., Beattie, H., Davies, E., \& Wootton, R. (2007-2008). Pre-registration nurses: An investigation of knowledge, experience and comprehension of e-health. Australian Journal of Advanced Nursing, 25(2), 78-83.

Eley, R., Fallon, T., Soar, J., Buikstra, E. \& Hegney, D. (2009). Barriers to use of information and computer technology by Australia's nurses: A national survey. Journal of Clinical Nursing, 18(8), 1151-1158. doi:10.1111/j.1365-2702.2008.02336.x

Elo, S., \& Kyngäs, H. (2008). The qualitative content analysis process. Journal of Advanced Nursing, 62(1), 107-115.

European Commission. (2011). eHealth Action Plan 2012-2020 - Innovative healthcare for the 21st centu$r y$. Retrieved from https://ec.europa.eu/digital-agenda/en/news/ehealth-action-plan-2012-2020innovative-healthcare-21st-century

EVA. (2015). The EVA Project: Evaluating the effects of a virtual communication environment for people who have aphasia. Retrieved from http://smcse.city.ac.uk/eva/

Eysenbach, G., \& CONSORT-EHEALTH Group. (2011). CONSORT-EHEALTH: Improving and standardizing evaluation reports of web-based and mobile health interventions. Journal of Medical Internet Research, 13(4), e126. doi:10.2196/jmir.1923

Gray, K., \& Sim, J. (2011). Factors in the development of clinical informatics competence in early career health sciences professionals in Australia: A qualitative study. Advances in Health Sciences Education, 16, 31-46. doi:10.1007/s10459-010-9238-3

Heerwegh, D., De Wit, K., \& Verhoeven, J. C. (2016). Exploring the self-reported ICT skill levels of undergraduate science students. Journal of Information Technology Education: Research, 15, 19-47. Retrieved from http://www.informingscience.org/Publications/2334

Hegarty, B., Penman, M., Kelly, O., Jeffrey, L., Coburn, D., \& McDonald, J, (2010). Digital Information Literacy: Supported Development of Capability in Tertiary Environments (Research Report). Retrieved from http://thehub.superu.govt.nz/sites/default/files/41953 Digital-Information-Literacy-ResearchReport-FINAL-pdf_ 0.pdf

Hercigonja-Szekeres, M., Ilakovac, V., \& Šolić, K. (2012). Medical students and e-health. In J. Mantas, S K. Andersen, M. C. Mazzoleni, B. Blobel, S. Quaglini, \& A. Moen. Studies in health technology and informatics, Volume 180 (pp.1150-1152). doi:10.3233/978-1-61499-101-4-1150

Hsieh, H., \& Shannon, S. E. (2005). Three approaches to qualitative content analysis. Qualitative Health Research, 15, 1277-1288. doi:10.1177/1049732305276687

Huang, C. (2012). Gender differences in academic self-efficacy: A meta-analysis. European Journal of Psychology of Education, 28(1), 1-35. doi:10.1007/s10212-011-0097-y 
Hyppönen, H., Kangas, M., Reponen, J., Nøhr, C., Villumsen, S., Koch, S., \& Kaipio, J. (2015) Nordic ehealth benchmarking: Status 2014. Copenhagen: Nordisk Ministerråd. doi: 10.6027/TN2015-539

Jones, C., Ramanau, R., Cross, S., \& Healing, G. (2010). Net generation or digital natives: Is there a distinct new generation entering university? Computers \& Education, 54, 722-732. doi:10.1016/j.compedu.2009.09.022

Katz, R. N. (2005). Foreword: Growing up digital. In J. B. Caruso \& R. Kvavik (Eds.), ECAR study of students and information technology, 2005: Convenience, connection, control and learning. Volume 6 (pp.5-8). Retrieved from http://www.educause.edu/library/resources/ecar-study-students-andinformation-technology-2005-convenience-connection-control-and-learning

Kennedy, G. E., Judd, T. S., Churchward, A., Gray, K., \& Krause, K. (2008). First year students' experiences with technology: Are they really digital natives? Australasian Journal of Educational Technology, 24, 108-122. Retrieved from http://www.ascilite.org.au/ajet/ajet24/kennedy.html

Kirkwood, A., \& Price, L. (2005). Learners and learning in the twenty-first century: What do we know about students' attitudes towards and experiences of information and communication technologies that will help us design courses? Studies in Higher Education, 30, 257-274. doi: $10.1080 / 03075070500095689$

Knowles, M. (1990). The adult learner: A neglected species (4th ed.). Houston, TX: Gulf Publishing.

Krippendorff, K. H. (2004) Content analysis: An introduction to its methodology (3 ${ }^{\text {rd }}$ ed.). Thousand Oaks, CA: Sage Publications.

Kubiatko, M., \& Vlckova, K. (2010). The relationship between ICT use and science knowledge for Czech students: A secondary analysis of PISA. International Journal of Science and Mathematics Education, 8(3), 523-543. doi:10.1007/s10763-010-9195-6

Kvasny, L., Joshi, K. D., \& Trauth, E. M. (2011). The influence of self-efficacy, gender stereotypes and the importance of IT skills on college students' intentions to pursue IT careers. Proceedings of the 2011 iConference. Doi:10.1145/1940761.1940831

Kvavik, R. B. (2005) Convenience, communications and control: How students use technology. In D. Oblinger \& J. Oblinger (Eds.), Educating the net generation (pp. 7.1-7.20). Retrieved from https://net.educause.edu/ir/library/pdf/PUB7101.pdf

Lam M. K., Nguyen M., Lowe R., Nagarajan S. V., \& Lincoln M. (2014). "I can do it”: Does confidence and perceived ability in learning new ICT skills predict pre-service health professionals' attitude towards engaging in e-Healthcare? Studies in Health Technology and Informatics (pp. 60-66). Amsterdam: IOS Press. doi:10.3233/978-1-61499-427-5-60

Lluch, M. (2011). Healthcare professionals' organisational barriers to health information technologies - A literature review. International Journal of Medical Informatics, 80, 849-862. doi:10.1016/j.ijmedinf.2011.09.005

Lowe, S., Adams, R., \& O'Kanne, A. (2007). A framework for the categorization of the Australian health professional workforce. Services for Australian Rural and Remote Allied Health. Retrieved from http://www.sarrah.org.au/site/index.cfm?leca=283\&module=FILEMANAGER\&did=6547997\&page_c ategory code $=6230 \&$ page $\mathrm{id}=98080$

Molka-Danielsen, J., \& Balandin, S. (2011). Design of a learning activity in Second Life: Active teaching of social educators. In A. Cheney \& R. L. Sanders (Eds.), Teaching and learning in $3 D$ immersive worlds: Pedagogical models and constructivist approaches (pp.112-128). Hershey, PA: IGI Global.

National Broadband Network Company. (2015). Learn about the NBN. Retrieved from: http://www.nbnco.com.au/about-the-nbn.html

Ong, C-S. \& Lai, J-Y (2006). Gender differences in perceptions and relationships among dominants of elearning acceptance. Computers in Human Behavior, 22, 816-829. doi:10.1016/j.chb.2004.03.006 
Padilla-Meléndez, A., del Aguila-Obra, A. R., \& Garrido-Moreno, A. (2013). Perceived playfulness, gender differences and technology acceptance model in a blended learning scenario. Computers and Education, 63, 306-317. doi:10.1016/j.compedu.2012.12.014

Prensky, M. (2001). Digital natives, digital immigrants. On the Horizon, 9(5), 1-6. doi: $\underline{10.1108 / 10748120110424816}$

Prensky, M. (2007). How to teach with technology: Keeping both teachers and students comfortable in an era of exponential change. Emerging technologies for learning, 2, 40-46. Coventry, UK: BECTA. Retrieved from http://xploit-eu.com/pdfs/PRENSKY\%20\%20How $\% 20$ to\%20teach\%20with\%20technology.pdf

World Health Organization [WHO] \& International Telecommunications Union [ITU]. (2012). National eHealth Strategy Toolkit. Retrieved from http://apps.who.int/iris/bitstream/10665/75211/1/9789241548465_eng.pdf 


\section{Appendix}

\section{Health Sciences Student eHealth Skills}

\section{A. About You}

1. How old did you turn at your last birthday?

2. What is your gender (please select as appropriate) $\square$ Male $\square$ Female

3.Are you a $\square$ Undergraduate or $\square$ Postgraduate Student

4. What degree are you enrolled in?

$\begin{array}{ll}\square \text { BHIthSci } & \square \text { BHIthSci and Master of Nursing } \\ \square \text { BAppSci (Speech Pathology) } & \square \text { BAppSci (Physiotherapy) } \\ \square \text { BAppSci (Occupational Therapy) } & \square \text { BAppSci ((MRS) Diagnostic Radiography) } \\ \square \text { BAppSci (Exercise and Sport Science) } & \square \text { BAppSci (Exercise and Physiology) } \\ \square \text { BAppSci (Exercise and Sport Science)/Master of Nutrition and Dietetics } \\ \square \text { Honours } \\ \square \text { Other, please specify }\end{array}$

$\square$ Master of Occupational Therapy $\quad \square$ Master of Speech Language Pathology

$\square$ Master of Rehabilitation Counselling $\quad \square$ Graduate Diploma in Rehabilitation Counselling

$\square$ Master of Diagnostic Radiography $\quad \square$ Master of Exercise Physiology

$\square$ Master of Physiotherapy

$\square$ Other, please specify

$\square$ Master by Research (MAppSci) $\quad \square \mathrm{PhD}$

5. How many semesters have you COMPLETED of your current degree (i.e. undergone all assessments and received your grades)?

6. What Health profession are you working towards?

$\square$ Corporate role in health $\square$ Diagnostic Radiographer $\square$ Exercise and Sport Scientist

$\square$ Exercise Physiologist $\square$ Nursing $\square$ Nutritionist / Dietician

$\square$ Occupational Therapist $\quad$ Physiotherapist

$\square$ Unsure

$\square$ Other, please specify

7. On a scale of 1-6 (1 being not-proficient and 6 very proficient)

How proficient do you feel you are in written English?

How proficient do you feel you are in spoken English?

8. Have you taken any IT related subjects before? $\square$ Yes

If yes, please specify 


\section{B. About eHealth}

9. What do you think eHealth is?

10. List 5 ways in which you are aware of technology is being used in healthcare management and/or delivery, if unsure state UNSURE (please do not leave blank):

i.

ii.

iii.

iv.

v.

\section{About Your view of eHealth}

11. For the purpose of this survey, eHealth is defined as the use of Information and Communication Technologies (ICT) in the delivery and management of healthcare services.

For each of the following statements about eHealth, please select one response that best reflects how you feel or would behave:

$$
1 \text { = Strongly Agree } \quad 2=\text { Agree } \quad 3 \text { = Disagree } \quad 4 \text { = Strongly Disagree }
$$

\begin{tabular}{|c|c|c|c|c|}
\hline Items & \multicolumn{4}{|c|}{ Response } \\
\hline Engaging in eHealth would improve patient/client care. & 1 & 2 & 3 & 4 \\
\hline The information I get from electronic health records help me give better care to patients. & 1 & 2 & 3 & 4 \\
\hline Using ICT make my communication with other health professionals faster. & 1 & 2 & 3 & 4 \\
\hline $\begin{array}{l}\text { 4. I worry that the use of eHealth applications in healthcare delivery may undermine patient } \\
\text { confidentiality. }\end{array}$ & 1 & 2 & 3 & 4 \\
\hline I believe that eHealth can help us deliver individualised care. & 1 & 2 & 3 & 4 \\
\hline 6. Using ICT would make my communication with other health professionals less reliable. & 1 & 2 & 3 & 4 \\
\hline The cost of implementing eHealth would be better used to employ more staff. & 1 & 2 & 3 & 4 \\
\hline $\begin{array}{l}\text { 8. The time I spend with patients would reduce because of the time I would spend working with } \\
\text { eHealth tools. }\end{array}$ & 1 & 2 & 3 & 4 \\
\hline 9. I think we are in danger of letting eHealth take over traditional healthcare practices. & 1 & 2 & 3 & 4 \\
\hline 10. eHealth helps to improve the way healthcare is delivered. & 1 & 2 & 3 & 4 \\
\hline $\begin{array}{l}\text { 11. The speed with which I can access information using eHealth applications will help me give better } \\
\text { care to patients. }\end{array}$ & 1 & 2 & 3 & 4 \\
\hline 12. Time spent on eHealth is out of proportion to its benefits. & 1 & 2 & 3 & 4 \\
\hline 13. Use of electronic health records would be more of a hindrance than a help to patient care. & 1 & 2 & 3 & 4 \\
\hline 14. I feel there are too many eHealth devices around now. & 1 & 2 & 3 & 4 \\
\hline 15. Engaging in eHealth would make healthcare staff less productive. & 1 & 2 & 3 & 4 \\
\hline 16. Engaging in eHealth is more trouble than it's worth. & 1 & 2 & 3 & 4 \\
\hline
\end{tabular}

Adapted from Ward, R., Pollard, K., Glogowska, M., \& Moule, P. (2006). Information Technology Attitude Scales for Health (ITASH): Project Report. Bristol: Faculty of Health and Social Care, University of the West of England. http://hsc.uwe.ac.ul/netresearch/Data/Sites/1/Gallenimages/Research/ITASH\%20Report(1).PDF 


\section{About Your use of ICT}

12. Which of the following ICT devices do you own? (select all that are applicable to you)

- Desktop computer

- Laptop/notebook computer

- Tablet computer (e.g. iPad, Galaxy)

- Mobile phone

o smartphone (Internet capable)

o simple phone (not Internet capable)

- e-Reader (e.g. Sony e-Reader, Kindle, Kobo)

- mp4 player (video capable, not including smart phone)

- mp3 player (audio only, not including smart phone)

- Games Console (e.g. Xbox, PS3, Nintendo Wii)

- Portable Games Console (e.g. Nintendo DX, PSP etc)

- Other, please specify

13. How often do you use the following software?

\begin{tabular}{|l|c|c|c|c|c|c|c|}
\hline & Never & Monthly & $\begin{array}{c}\text { Once a } \\
\text { week }\end{array}$ & $\begin{array}{c}1-2 \\
\text { times } \\
\text { a week }\end{array}$ & $\begin{array}{c}3-4 \\
\text { times a } \\
\text { week }\end{array}$ & $\begin{array}{c}5-6 \\
\text { times } \\
\text { a week }\end{array}$ & $\begin{array}{c}\text { Every } \\
\text { Day }\end{array}$ \\
\hline Study/work related software: & & & & & & & \\
\hline Word processing & $\square$ & $\square$ & $\square$ & $\square$ & $\square$ & $\square$ & $\square$ \\
\hline Presentation & $\square$ & $\square$ & $\square$ & $\square$ & $\square$ & $\square$ & $\square$ \\
\hline Spreadsheet & $\square$ & $\square$ & $\square$ & $\square$ & $\square$ & $\square$ & $\square$ \\
\hline Database & $\square$ & $\square$ & $\square$ & $\square$ & $\square$ & $\square$ & $\square$ \\
\hline Data analysis & $\square$ & $\square$ & $\square$ & $\square$ & $\square$ & $\square$ & $\square$ \\
\hline Video conferencing software & $\square$ & $\square$ & $\square$ & $\square$ & $\square$ & $\square$ & $\square$ \\
\hline Audio editing software & $\square$ & $\square$ & $\square$ & $\square$ & $\square$ & $\square$ & $\square$ \\
\hline Video editing software & $\square$ & $\square$ & $\square$ & $\square$ & $\square$ & $\square$ & $\square$ \\
\hline Image editing software & $\square$ & $\square$ & $\square$ & $\square$ & $\square$ & $\square$ & $\square$ \\
\hline
\end{tabular}




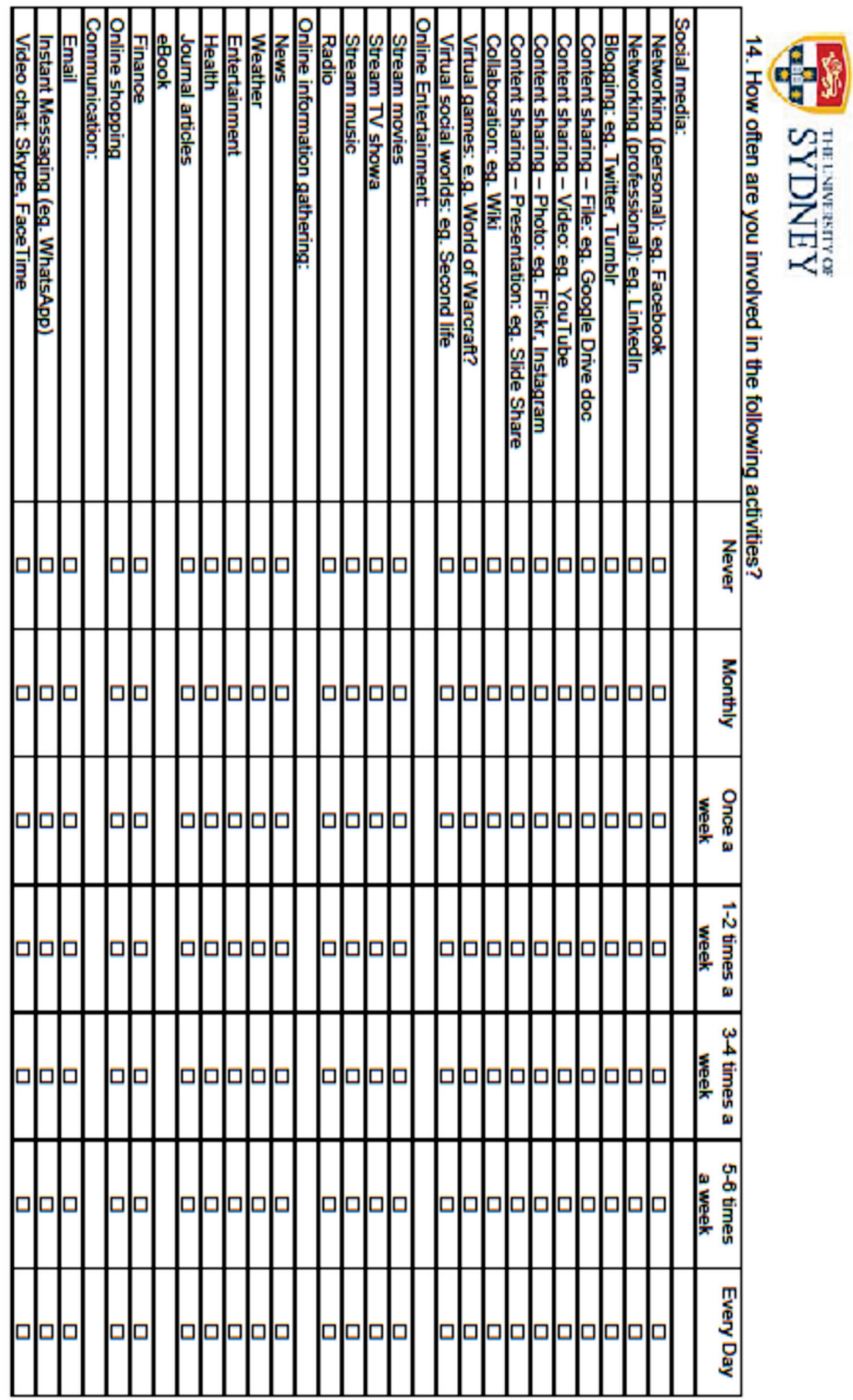




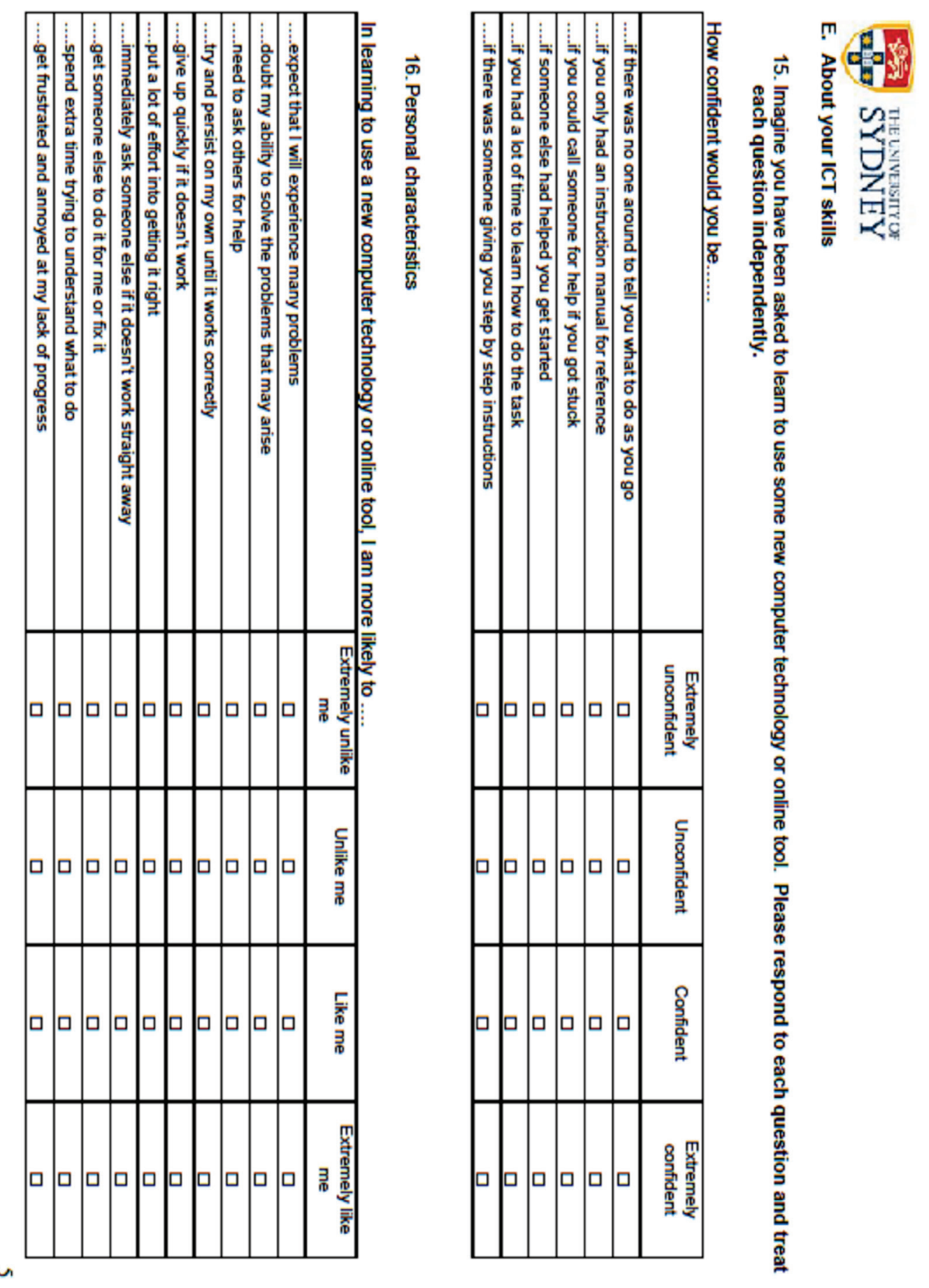




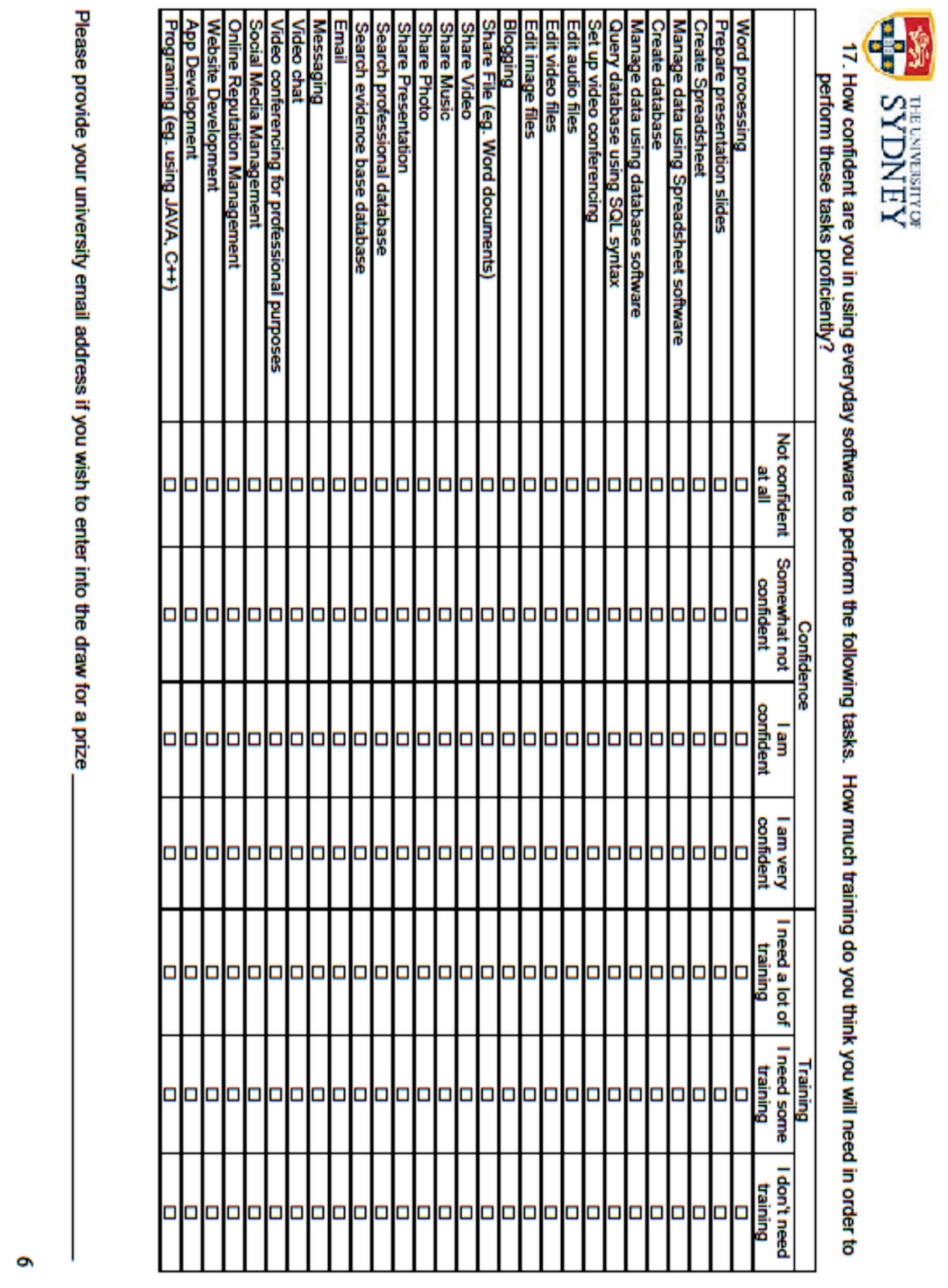




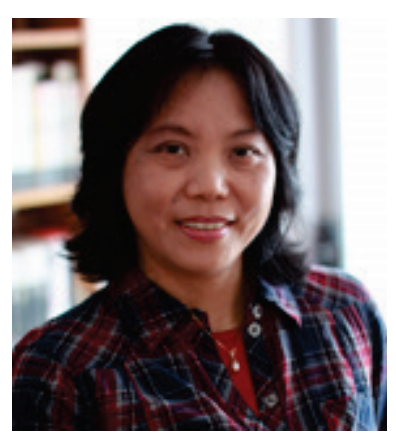

\section{Biographies}

Dr Mary Lam is a Health Informatician with a background in bioinformatics, health informatics and health information management. Her expertise is in the design and development of information systems as well as the linkage, management and analysis of large scale health system datasets. Mary is currently working as a Lecturer in eHealth.

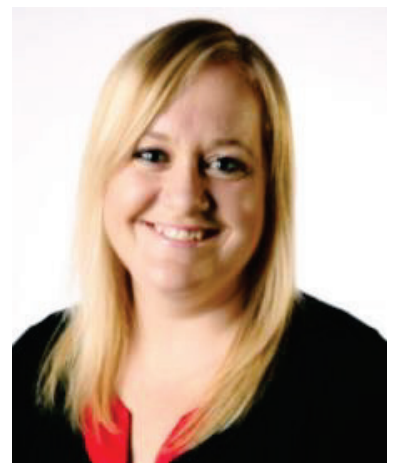

Dr Monique Hines is a Postdoctoral Research Associate at the University of Sydney. She conducts research into allied health service delivery for people with disability living in rural and remote areas. She is specifically interested in the potential for eHealth to promote equity in access, and to support interdisciplinary practice in allied health.

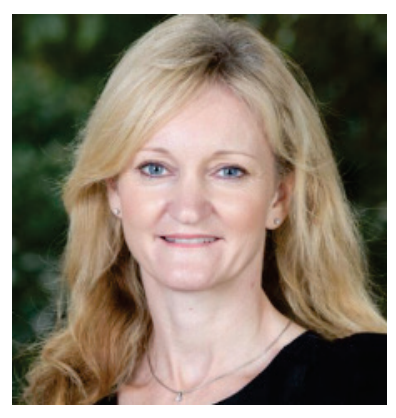

Dr Robyn Lowe is a speech pathologist and researcher at the University of Sydney. Her work involves developing and evaluating online speech and anxiety treatments for people who stutter. Robyn's research interests include exploring the psychological aspects associated with stuttering and how this impacts the long-term maintenance of speech treatment benefits.

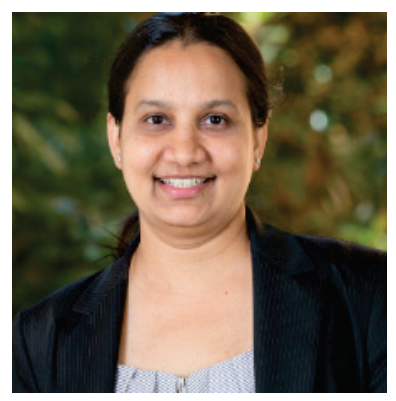

Dr. Srivalli Nagarajan is a postdoctoral research associate in the Work Integrated Learning portfolio at the Faculty of Health Sciences, The University of Sydney. Her research interests are: work readiness expectations of employers, universities and graduates and alignment of university curricula with industry needs. 


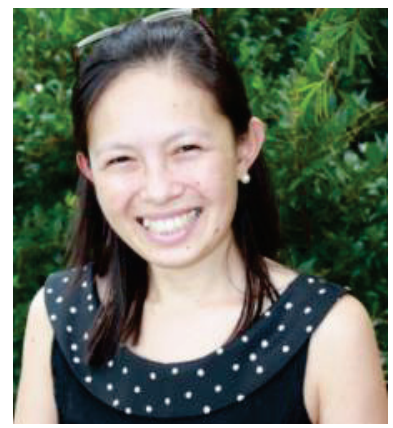

Dr Melanie Keep is a lecturer at the Faculty of Health Sciences of The University of Sydney. Her research spans cyberpsychology, eHealth and eLearning. She is interested in the effects of using technology on health and explores how technology can improve health delivery, access to health and student learning.

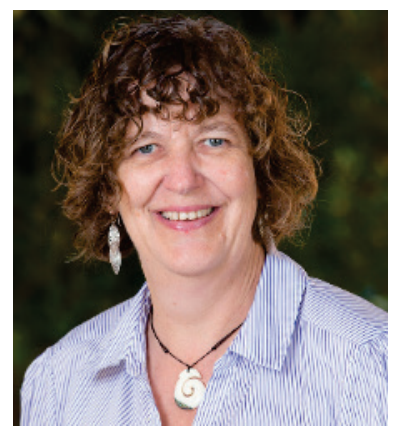

Dr Merrolee Penman is Senior Lecturer and Director of Work Integrated Learning at the University of Sydney. Her research interests include exploring how technology, specifically social media can support the ongoing learning needs of students and allied health practitioners. Her overarching interest is in understanding what facilitates learning to learn.

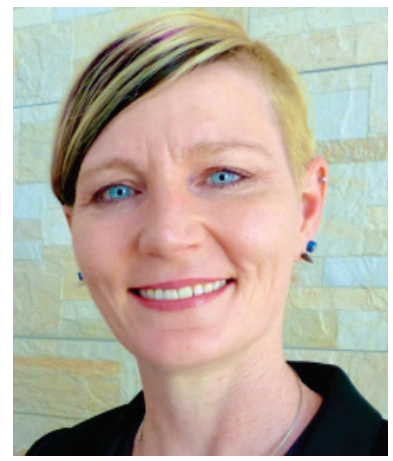

Dr Emma Power is a speech pathologist and lecturer at the University of Sydney. Her research and teaching interests include knowledge transfer and exchange (KTE), neurogenic cognitive-communication disorders, e-learning and $\mathrm{m}$-health solutions for learning and teaching and rehabilitation. 